\title{
Effect on superhydrophobic surfaces on electrical porcelain insulator, improved technique at polluted areas for longer life and reliability
}

\author{
Isaac Ramalla ${ }^{1 *}$, Rajeev K Gupta ${ }^{2}$, Kamal Bansal ${ }^{3}$ \\ ${ }^{I}$ Research scholar, University of Petroleum and Energy Studies, Dehradun, Uttarakhand, India \\ ${ }^{2}$ Head of the Department, Department of Physics, University of Petroleum and Energy Studies, Dehradun, Uttarakhand, India \\ ${ }^{3}$ Dean, College of Engineering, University of Petroleum and Energy Studies, Dehradun, Uttarakhand, India \\ *Corresponding authorE-mail: isaacr@ddn.upes.ac.in
}

Copyright $\odot 2015$ Isaac Ramalla et al. This is an open access article distributed under the Creative Commons Attribution License, which permits unrestricted use, distribution, and reproduction in any medium, provided the original work is properly cited.

\begin{abstract}
This paper proposes a novel technique to enhance the stability of high-voltage insulators, which are affected due to the presence of dust, contamination, electrical stresses in a high moisture content environment. These result in puncture of insulators and heavy loss due to power outages in the transmission lines. To extend its stability, powdered coating is done on the insulators which have insulation property and super hydrophobicity. In this paper, the authors were inspired by the 'lotus effect', and a nano size powder was developed by sol - gel method and coating is done on the porcelain insulator surface, which passes-out all the electrical testing standards and maintains its insulation property with super hydrophobic nature. The water droplet contact angle of $158.8^{\circ}$ and a sliding angle of $8^{0}$ indicate the super hydrophobic nature on the surface of insulator. The insulator was kept in a highly polluted environment for six months at different locations where no dust was collected on the insulator when compared with an uncoated insulator.
\end{abstract}

Keywords: Post Insulator; Contamination; Electrical Stress; Superhydro Phobicity; Self-Cleaning Surface; Polluted Conditions; Nano Coated and Uncoated Post Insulator.

\section{Introduction}

In high-voltage engineering applications, the main drawback with the glass/porcelain insulators is that rain drop sticks to its surface, even when it is placed inclined or vertically. The interruption caused due to breakdown cause huge economic loss to power companies, and it is a big task for the line inspectors to find out the fault due to insulator puncture on the power lines. Various remedial measures were suggested in the due course of time but could not satisfy the problem. Another better remedial measure is suggested after few studies and experiment, which are discussed in this paper with some necessary requirements and changes.

In our present study, the superhydrophobic surface based on lotus leave is explored to maintain the desired properties for self-cleaning. Parameters in controlling bead-up and roll-off characteristics of water droplets were investigated on different model surfaces. This is an effective way to reduce the adhesion of raindrop so as to decrease the contact time and area. The effect of roughness on surface wetting is scale-dependent. Besides the surface hydrophobicity, the surface roughness can be more important in achieving de-wetting surfaces.

A water droplet sticks on mostly on the air like the fakir state. As explained by Cassie [1, 3], a liquid droplet residing on the composite surface (here especially for the composite surface of air and solid) has a resulting contact angle in the form of $\cos \theta^{*}=-1+\varphi_{s}(1+\cos \theta)$, where in above equation ' $\varphi_{\mathrm{s}}$ 'designates the fraction of solid surface being in touch with the liquid drop, and ' $\theta$ ', is the intrinsic contact angle of the flat surface with the same chemical components. Various techniques have been developed to produce the lotus leaf effect such as phase separation [4], chemical vapour deposition [5, 6], sol-gel processing [7-11], chemical etching [12, 13] electro spinning [14-18], self-assembly [19-23]. Most of the techniques require special equipment and cannot be used on different kind of materials. 
In this paper, we used advanced sol-gel technique [24] to generate lotus leaf effect; the super hydrophobic surfaces are fabricated by employing two kinds of approaches: creating hierarchical structures on hydrophobic surfaces, and then chemically modified with a low surface free energy material, suchastetraethoxysilane, (TOES) perflouorodiethlytrioxysilane (PDTS). Silicon wafer of $12 \mathrm{~mm}$ x $3 \mathrm{~mm}$ size is taken and coated with the precursor with spray coating and similarly a fine piece of $0.5 \mathrm{~mm} \times 1 \mathrm{~mm}$ size porcelain material is taken, and spray coated with precursor of $\mathrm{SiO}_{2}$ powder size of $15 \mathrm{~nm}$. After heating furnace at $348 \mathrm{~K}$ for 30 minutes, natural cooling was done and finally diluted PDTS was spray coated. The modified both samples and again heated in a hot air oven for two hours and cooled in room temperature.

\section{Experimental sections}

\subsection{Reagents}

Tetraethoxysilane(TEOS,AR),(Merck, Germany),Sulphuric Sulphuric acid, acid, Silica Powder, 1H, 1H, 2H, 2HPerfluorodecyltriethoxysilane (PDTS,AR)( Merck, Germany), double distilled water, Ammonium hydroxide $\mathrm{NH}_{4} \mathrm{OH}$, Nitric acid $\left(\mathrm{HNO}_{3}\right)$, Hydrochloric acid $(\mathrm{HCl})$.

\subsection{Experimental procedure}

The precursor used to manufacture a silica coating with hierarchical structures is a suspension of $\mathrm{SiO}_{2} \mathrm{sol}_{\text {and }} \mathrm{SiO}_{2}$ powder. The $\mathrm{SiO}_{2}$ sol was prepared by means of sol-gel method as the following process: $45.6 \mathrm{~mL}$ TEOS and $54.8 \mathrm{~mL}$ ethanol were added to a flask and stirred vigorously at room temperature for $30 \mathrm{~min}$., and then conc. $\mathrm{HNO}_{3}$ with $\mathrm{pH}=1$ and $3 \mathrm{ml}$ of dil. $\mathrm{HCl}$ was added and stirred for 30 minutes. The hydrolysis reaction was performed forone hour, and then the solution mixture is allowed for ageing for one day under room temperature. The silica powder, with a diameter of the $20-30 \mathrm{~nm}$ mixture was heated and baked at $70^{\circ} \mathrm{C}$ for $1 \mathrm{hr}$. A mixed ratio of 1 drop of PDTS in 50ml ethanol was added drop by drop and spray coating was done on the fine piece of porcelain insulators tiny sample $\left(\mathrm{S}_{1}\right)$, silicon wafer $\left(\mathrm{S}_{2}\right)$ and $70 \mathrm{kN} 33 \mathrm{kV}$ post insulator bushing $\left(\mathrm{S}_{3}\right)$. The insulator was dried at $348 \mathrm{~K}$ in a vacuum furnace for 30 min., and then baked for $1 \mathrm{hr}$ at $400 \mathrm{~K}$. After cooling down to ambient room temperature, the samples were tested. The super hydrophobic film was also coated on the microscope slides $\left(S_{4}\right)$ (see figure. 1) in the same way, and so obtained a sample was adopted for the characterization of structure and the test of super hydrophobic property as well. The coated and uncoated porcelain post insulator bushing was kept for observation in the different air polluted zones. After a six months period, the insulators are brought to laboratory and analysed for accumulation of dust formation on both the insulators with different polluted and climatic conditions and electrical properties are also tested by sending high voltage to the insulators.

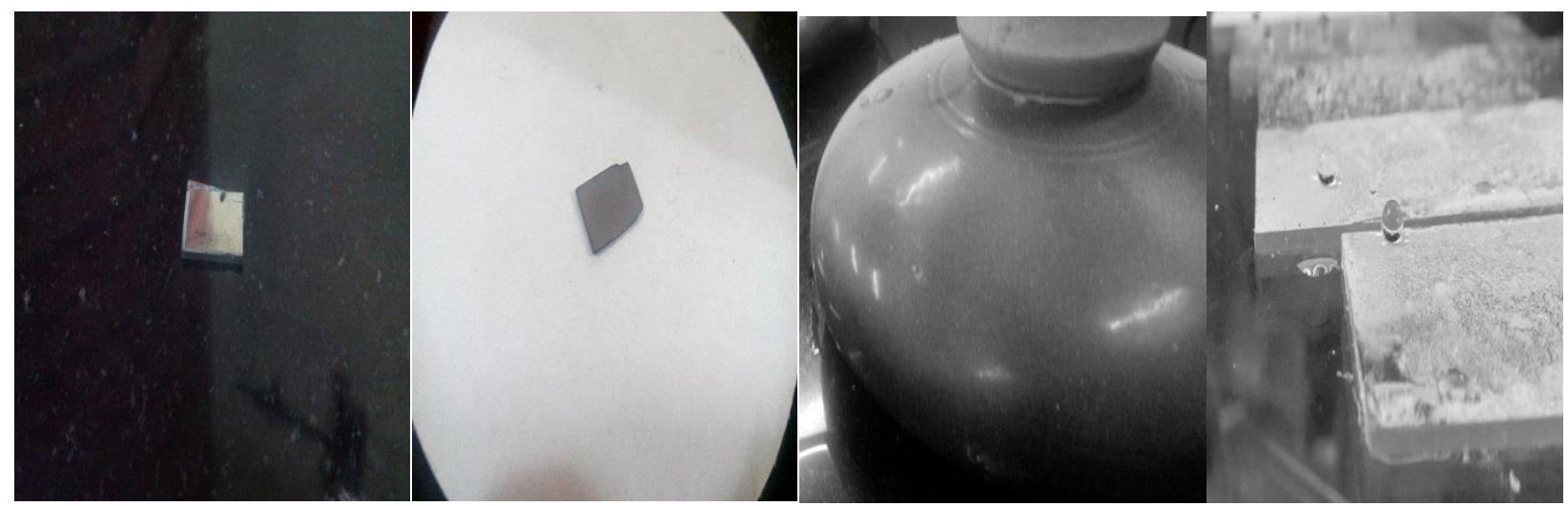

Fig. 1: Images of the Samples $\mathrm{S}_{1}, \mathrm{~S}_{2}, \mathrm{~S}_{3}$, and $\mathrm{S}_{4}$. (Left to Right)

\subsection{Characterisation}

The FTIR(Model PerkinElmer Spectrum Version 10.03.09), AFM (Model NanosurfNaio AFM atomic force microscope system) specimen samples characterization was done at Nano Research Laboratory, UPES, Dehradun and SEM, XRD at WIHG, Dehradun and IITR, Roorkee. The Electrical Post Insulator Testing was done at M/S Oblum Insulators, Hyderabad and authorised testing plant for insulators by CPRI, Hyderabad. 


\section{Results and discussion}

\subsection{Hierarchical structure of the coating}

The synthesis of $\mathrm{SiO}_{2}$ particles by sol - gel method was done by hydrolysis of TOES and multilevel condensation of the hydrolysis product, $\mathrm{Si}(\mathrm{OH})_{4}$. The catalyst used in the synthesis is acidic in nature. Various studies show that the size of the spherical silica particles is determined by the relative values of the rate constants for hydrolysis and polycondensation reactions, respectively. To reduce the particle size, fast hydrolysis and slow polycondensation are necessary, so the synthesis should be carried out in acidic condition; on the other hand, slow hydrolysis and fast polycondensation which happen in ammonia base condition, lead to ramified polymers. As in this case, the $\mathrm{HNO}_{3}$ and HClwas employed in the preparation of nano- $\mathrm{SiO}_{2}$ solution, and was thermally decomposed during the heating treatment of $\mathrm{SiO}_{2}$ powder.

\subsection{SEM analysis}

SEM is used to plot the size of the particle size and morphology of the prepared sol-gel $\mathrm{SiO}_{2}$ samples are predicted from SEM samples. Figure. 2 is the SEM image of $\mathrm{SiO}_{2}$ prepared by means of advancedsol-gel method described in experimentalsection. SEM images are taken from Sigma Scanning Electron Microscope from Carl Zeiss at Wadia Geological Research Institute and the images show that the single $\mathrm{SiO}_{2}$ particle is roughly spherical with the size of 7-8 $\mathrm{nm}$. The powdered $\mathrm{SiO}_{2}$ is also sphere-like, and with an average size of $50-60 \mathrm{~nm}$ at a width of $100 \mathrm{~nm}$ from the image. The SEM image shown in Figure. 2 resembles structure of Silica which makes the water droplet to stay in between two crystals and make the water droplet to float and roll easily as in the natural lotus leaf phenomenon and makes the low wettable and less surface tension and high contact angle surface.

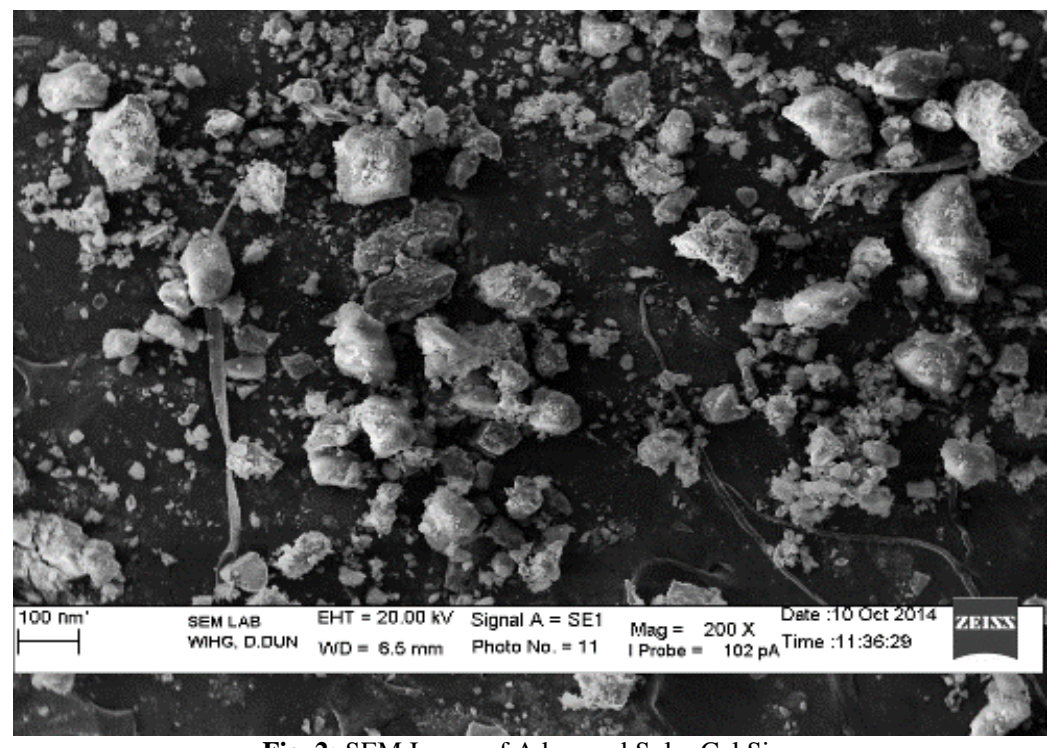

Fig. 2: SEM Image of Advanced Sol - Gel $\mathrm{SiO}_{2}$

\section{AFM image analysis}

AFM image of the $\mathrm{SiO}_{2}$ sample for both before and after coating is shown in Figures.3, 4 and 5. Surface morphology and roughness of the coatings was studied by using AFM (model NanosurfNaio AFM atomic force microscope system ) with a Si tip (with a radius $7 \mathrm{~nm}$, resonance frequency $299 \mathrm{kHz}$ ) in the non-contact mode under ambient conditions. Three Dimensional Atomic Force Microscopy (3D-AFM) image on surface coating (scan area $5 \times 5 \mathrm{~m}^{2}$ ). AFM analysis revealed that thin film of layer is highly porous it shows that the hydrophobicity of the advanced sol-gel $\mathrm{SiO}_{2}$ nanoparticles coated on silicon sheet and ceramic material. 


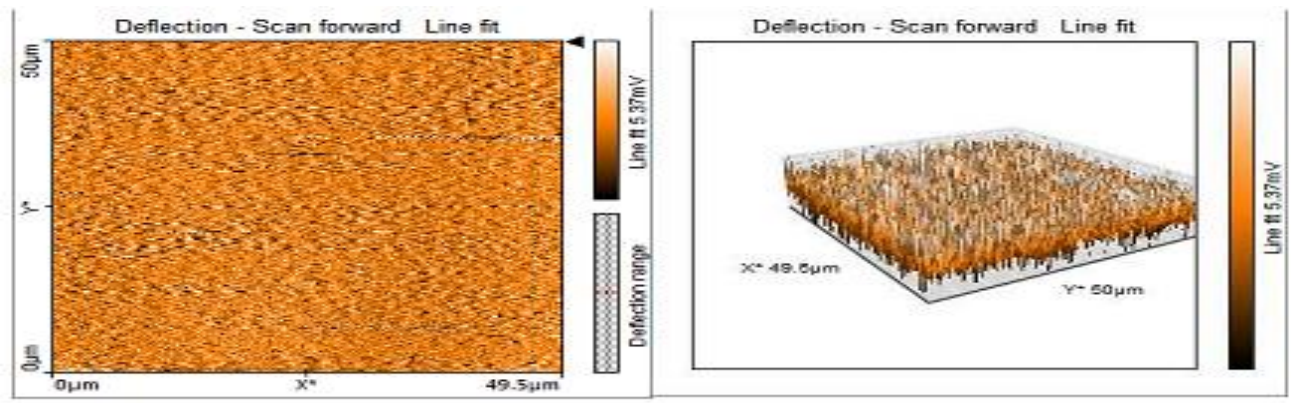

Fig. 3: Uncoated Porcelain Insulator Tiny Sample $\left(\mathrm{S}_{1}\right)$.

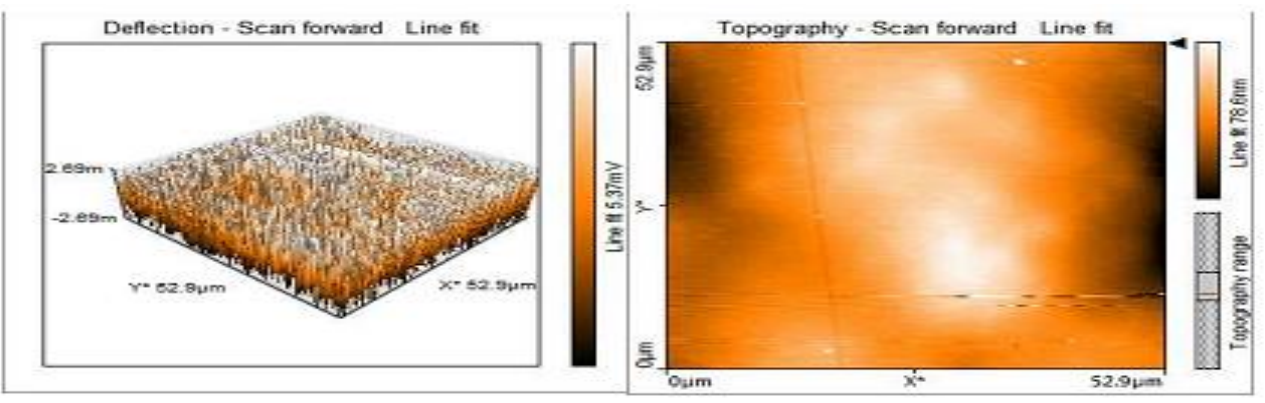

Fig. 4: Silicon Powder Coated Porcelian Insulator Sample.

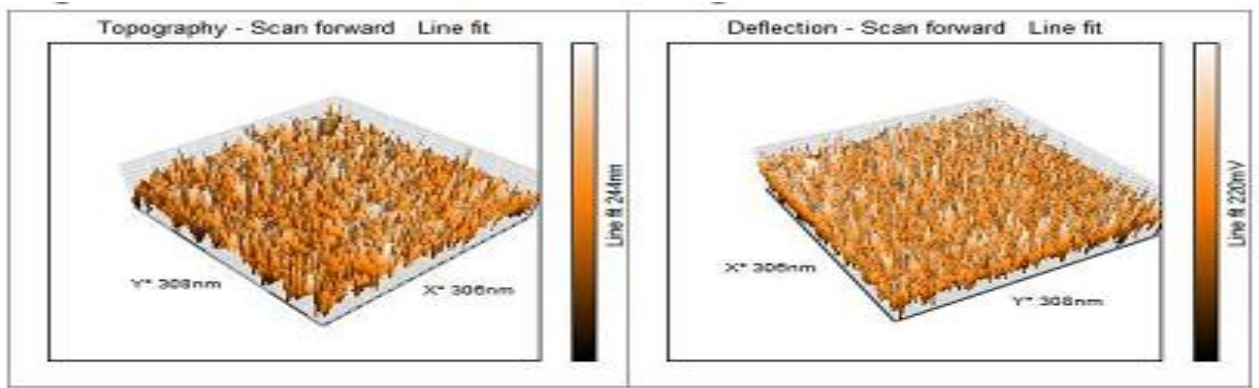

Fig. 5: Nano Coated Silica Sheet AFM Image For Sample $\left(S_{2}\right)$

\subsection{Superhydrophobic properties}

Coated superhydrophobic surface on which the static water contact angle reaches to 158.8 and sliding angle $8^{0}$ on a coated silicon wafer and small porcelain sample. The results from the AFM (see Figure.5), displayed a deposition of $\mathrm{SiO}_{2}$ nano particles with multi scaled rough surface, which traps enough air to repel the water drop. Therefore when water was dropped on the insulators, it could not adhere to the surface, even when it was forced upon externally.

Contact Angle Goniometer:

Water droplets was dropped on samples S1, S2 and S4 and are measured for contact angle at Nano Research Lab, University of Petroleum and Energy Studies on Kruss Model DSA 30. Contact angle showed the superhydrophobic nature on the three surfaces was around an average of more than $155^{\circ}$ at different areas on all the three samples and with a roll off angle of less than $8^{0}$ which are highly hydrophobic or can be called as superhydrophobic surface.

\subsection{FT-IR spectral analysis}

FT-IR spectrum (FT-IR model PerkinElmer Spectrum Version 10.03.09)of the as repaired composite is as shown in the Figure. 7 the percentage of transmittance peaks at $1099.32 \mathrm{~cm}^{-1}$ and $480-170 \mathrm{~cm}^{-1}$ are attributed to the Si-O-Si asymmetric stretching and bending vibrations. The peaks at broad absorption band $3440-3420 \mathrm{~cm}^{-1}$ and $1640-1630 \mathrm{~cm}^{-1}$ are due to the $-\mathrm{OH}$ groups of $\mathrm{SiO}_{2}$. FT-IR spectrum of the as prepared sol-gel silica after calcination suggests that the prepared $\mathrm{SiO}_{2}$ nanoparticles are pure and free from organic matter. Si-O- $\left(\mathrm{H}-\mathrm{H}_{2} \mathrm{O}\right)$ bending vibrations observed at near $966.37 \mathrm{~cm}^{-1}$ while peak at $804 \mathrm{~cm}^{-1}$ indicates in-plane bending vibrations of geminol groups. Peaks at $1099.32 \mathrm{~cm}^{-1}$ indicates Si-O-Si asymmetric stretching vibrations near $3454.31 \mathrm{~cm}-1$ denotes surface - $\mathrm{OH}$ group where the bending of $-\mathrm{OH}$ groups (adsorbed water molecules at $1630 \mathrm{~cm}^{-1}$ ). 


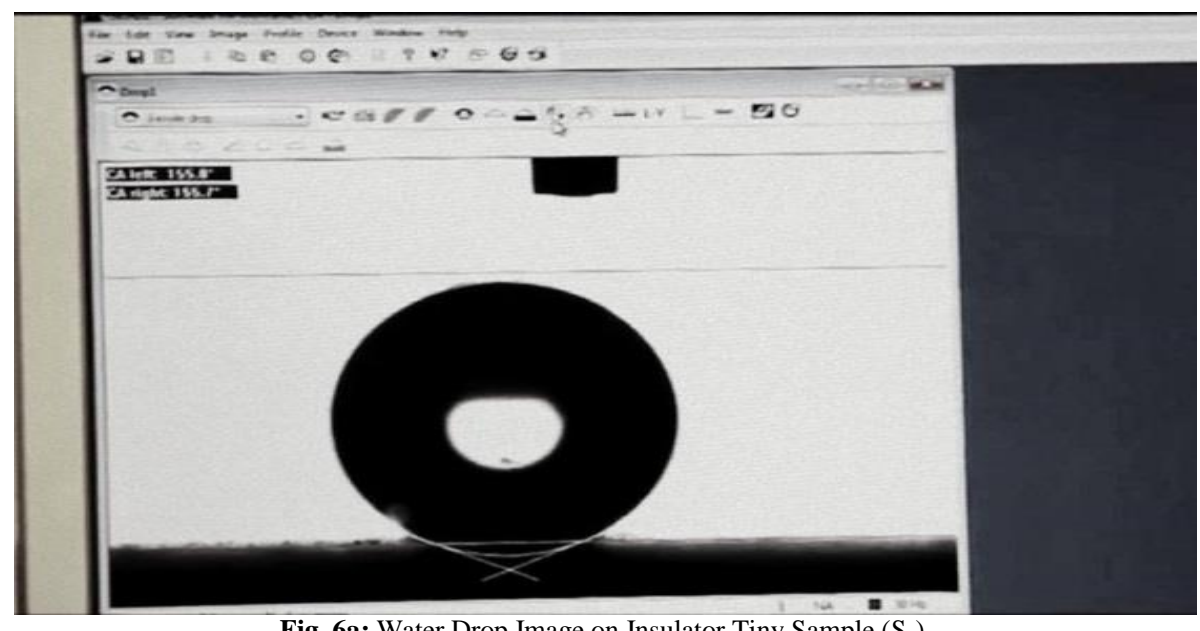

Fig. 6a: Water Drop Image on Insulator Tiny Sample $\left(\mathrm{S}_{1}\right)$.

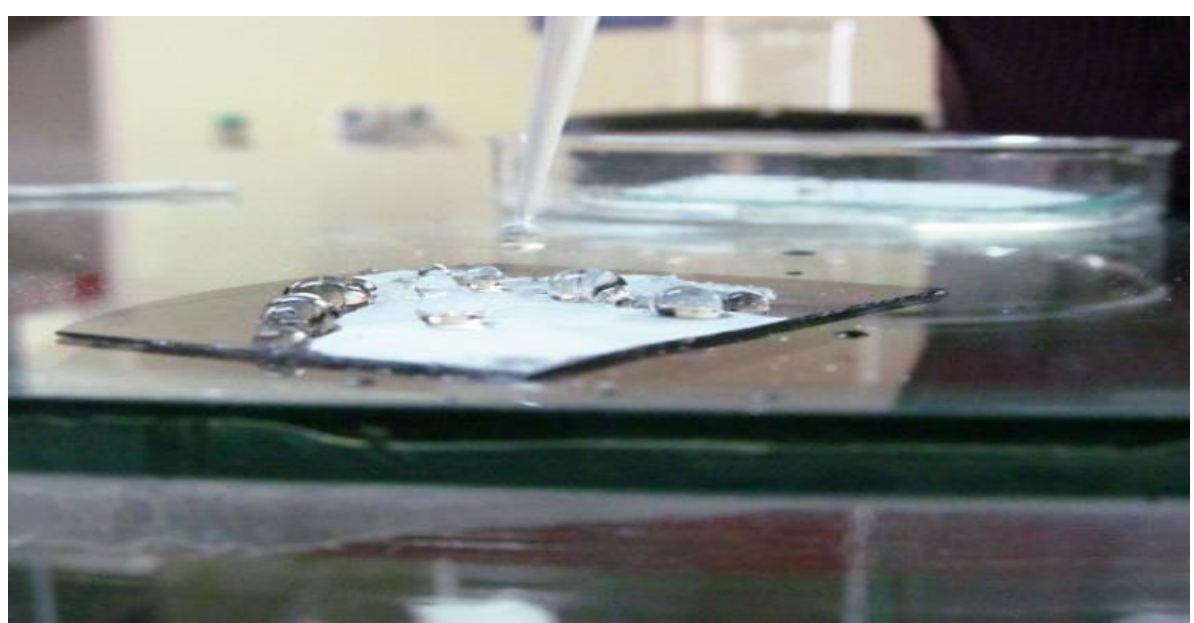

Fig. 6b: Specimen with Water Droplet Sample on Goniometer Silicon Wafer.

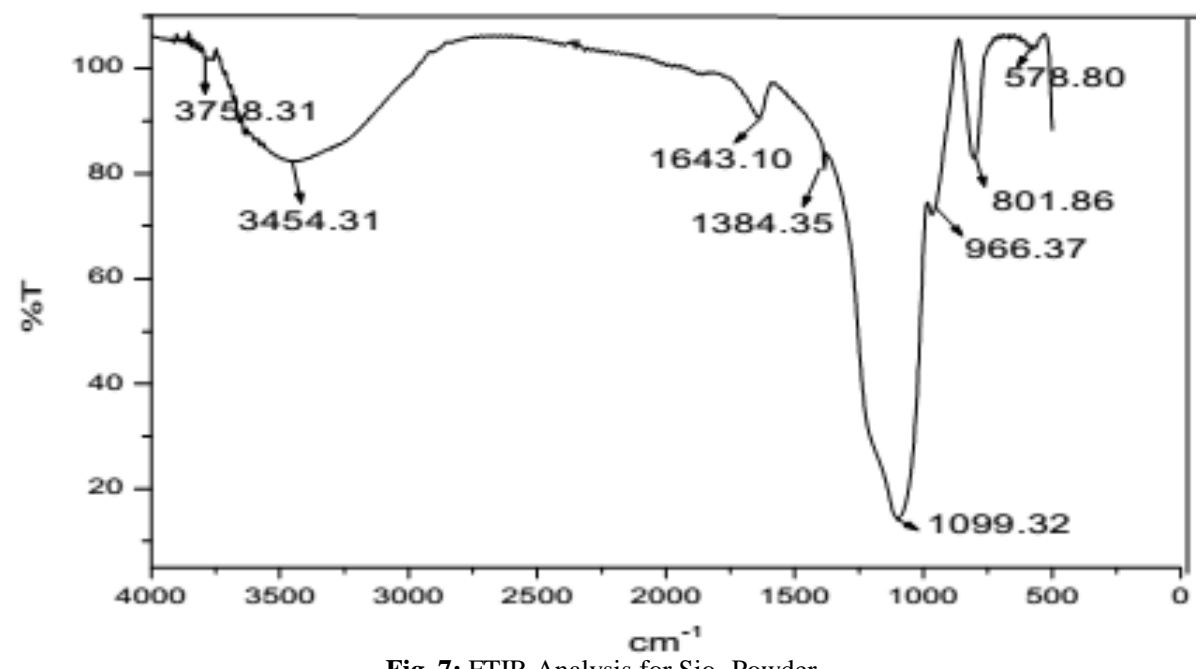

Fig. 7: FTIR Analysis for $\mathrm{Sio}_{2}$ Powder.

\section{Electrical characterization and analysis}

The post insulator bushing was subjected to various mechanical and electrical tests done by M/S: OBLUM Insulators according to IE and BS Standards. The tests performed where Routine testing and Acceptance Testing.

These testing were done to know the insulator behaviour after the deposition of dust on coated and uncoated insulators when these insulators were kept in moderately polluted areas for six months duration. 


\section{Insulator specification}

The post insulator bushing strings shall consist of standard discs for use in three phases, $50 \mathrm{~Hz} 33 / 11 \mathrm{KV}$ substation and to hold hot electricity conductors on poles, these post insulators are kept in a moderately polluted atmosphere. The discs shall be cap and pin, ball and socket type, radio interference and have characteristics as seen in Table.1 and all ferrous parts shall be hot dip galvanized as per the latest edition of IS 2629 . The zinc to be used for making sleeves shall be 99.95 \% pure. The insulator are procured from Tehri Distribution Power Limited, Power Transmission Corporation of Uttarakhand Limited for doing live testing and to analyse the real time scope for using this insulators with nano superhydrophobic coated material in polluted conditions. Uncoated porcelain insulator procured from Distribution Company is shown in Figure. 8.

Table 1: Post Porcelain Bushing Standards

\begin{tabular}{lllll}
\hline S.No & Type of String & Size $(\mathrm{mm})$ & Creepage Distance $(\mathrm{mm})$ & Mechanical Strength $(\mathrm{kN})$ \\
\hline 1 & Single suspension & 145 & 430 & 45 \\
2 & Double suspension & 255 & 430 & 70 \\
\hline
\end{tabular}

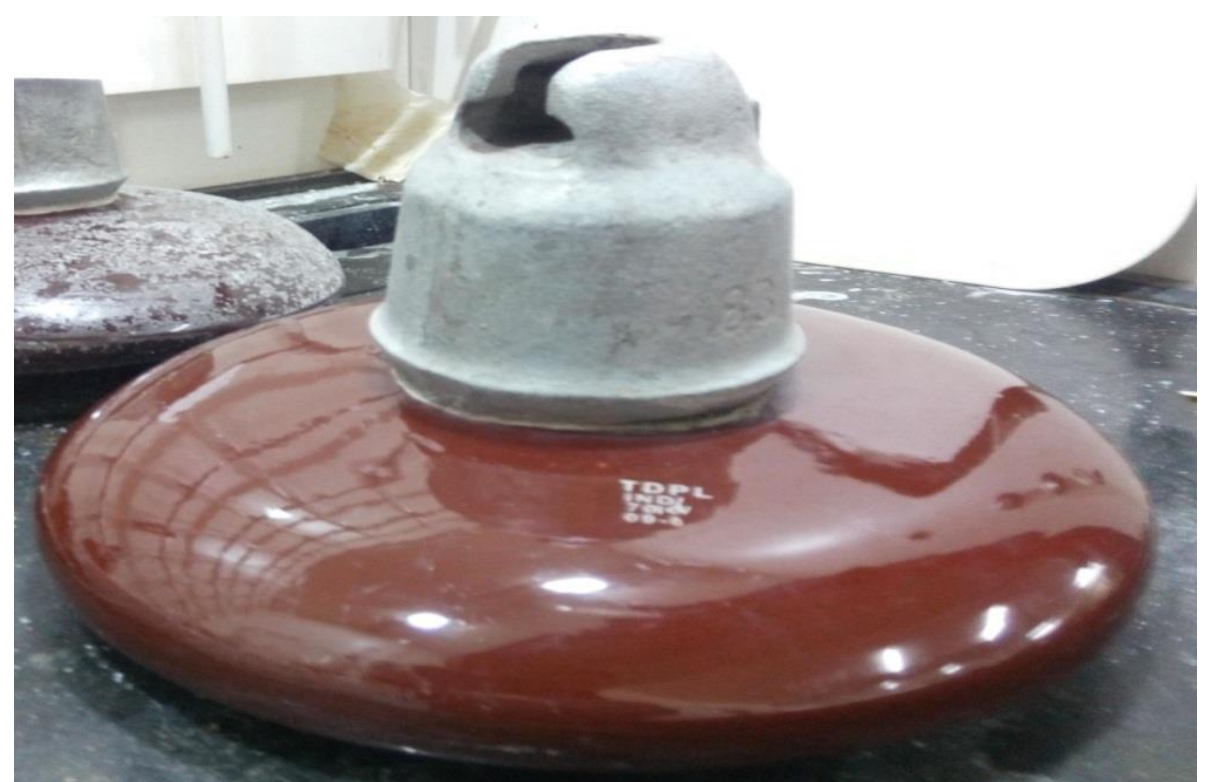

Fig. 8: Uncoated Insulator Post Insulator Bushing of 70kn from Tehri Distribution Power Limited, Power Transmission Corporation of Uttarakhand Limited.

\section{Insulator experimental preparation setup}

The three insulators which are coated with nano composite are hanged on the electrical poles at three different polluted areas for six months which could cover two of the Indian climatic conditions from month of March to august. The three locations are selected to the different polluted areas in three different locations.

\section{Setup conditions}

Location -1 :

This area is covered with trees and the level of the dust is low, at this place the setup is created in such a way that on the angular two insulators with coated and uncoated are hanged on either side and low voltage of $220 \mathrm{~V}$ is passed through it. This set up is kept for same duration and the surface is checked at regular intervals and observed for any deposition of dust on both the insulators. The angular was first tested in the laboratory (see Figure. 9.) for mechanical tests and after 30 days it was taken to the polluted location. 


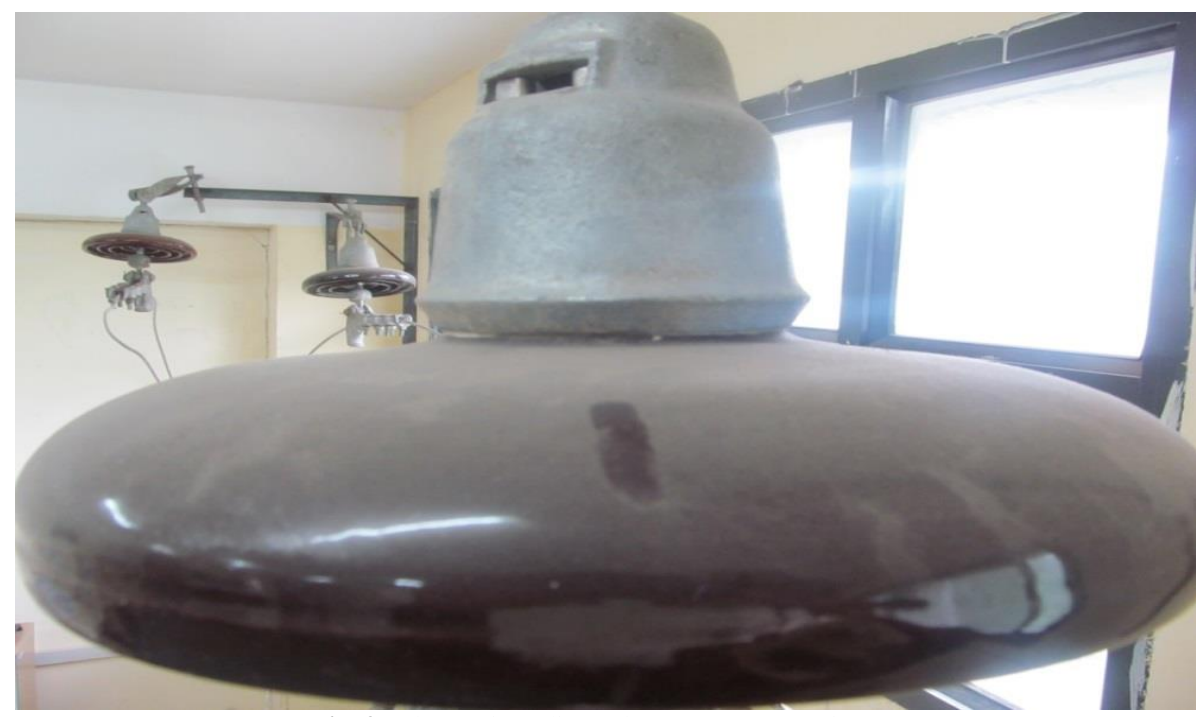

Fig. 9: Above Fig Indicate the Set Up at Location -1.

Location -2

At this location moderate dust level conditions, the location of these two coated and uncoated is kept at heavy traffic road side. These insulators are connected to live power conditions of $33 \mathrm{kV}$ line on a dead end double pole line where coated and uncoated insulators are connected on two different electric phases as shown in figure.10.

Location -3

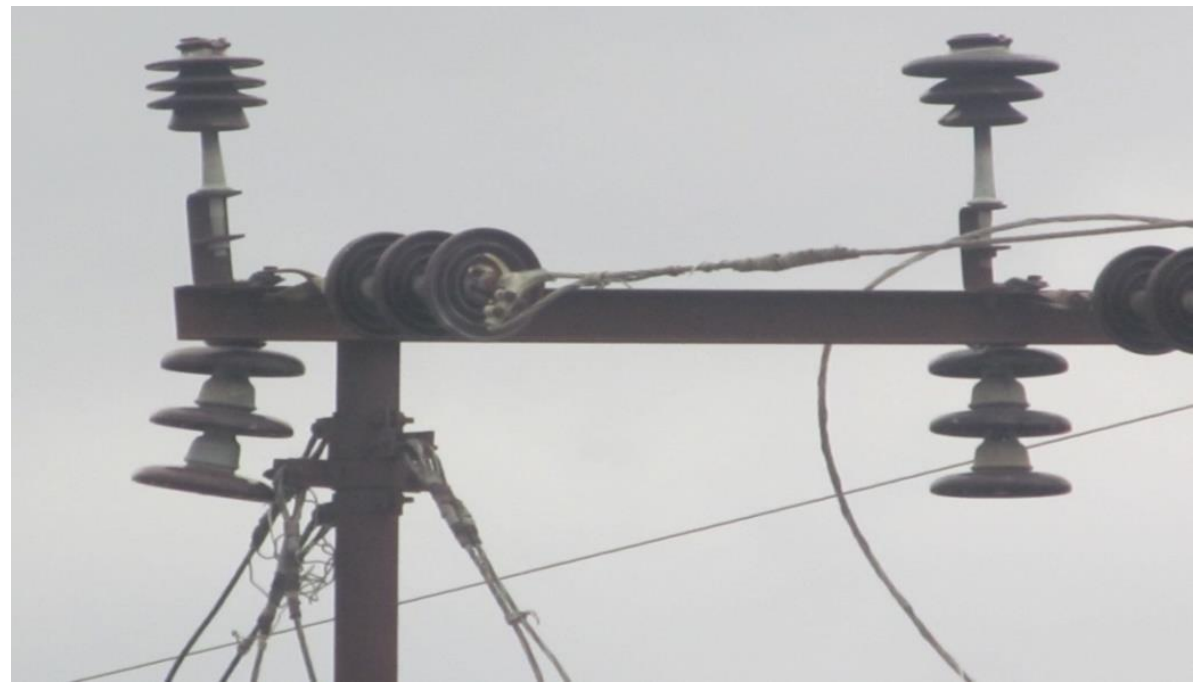

Fig. 10: Coated and Uncoated Post Insulator Was Kept at Dead End Electric Pole of 33kv Hot Line.

The set of coated and uncoated insulators are kept at an commercial building construction side where the dust level is moderate high. The setup is kept on at a place where the dust can be accumulated on the insulators as shown in Figure. 11.

\section{Observations and discussions}

Location -1

The two sets of insulators were taken from pole, and after clear examination in bright light, a very fine dust layer was found on the uncoated insulator and in this location rains have cleared the dust formation on the coated insulator. There was no dust on the insulator and the insulator was looking like a new coated insulator. There was no change in the colour or thickness of the coating on the insulators. The insulator is free from visual defects and there were no voids and cracks on the coated insulator. Insulating property was maintained on this nano coated insulator and it could withstand the electrical potential of 220 volts and no changes were seen on the coated insulator as shown in the figure. 12(a) and 12 (b). 


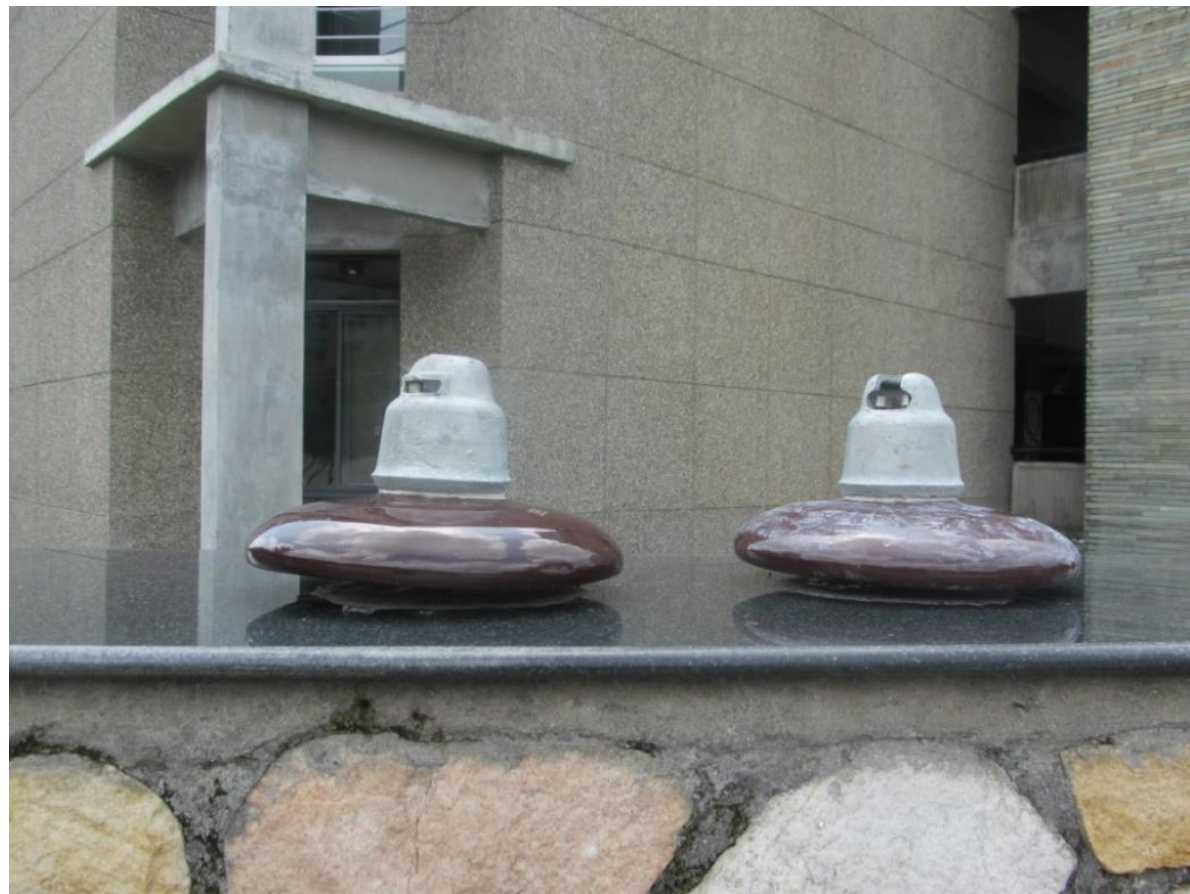

Fig. 11: Coated and Uncoated Insulator Is Kept for Observation in a Commercial Building Construction Polluted Area.

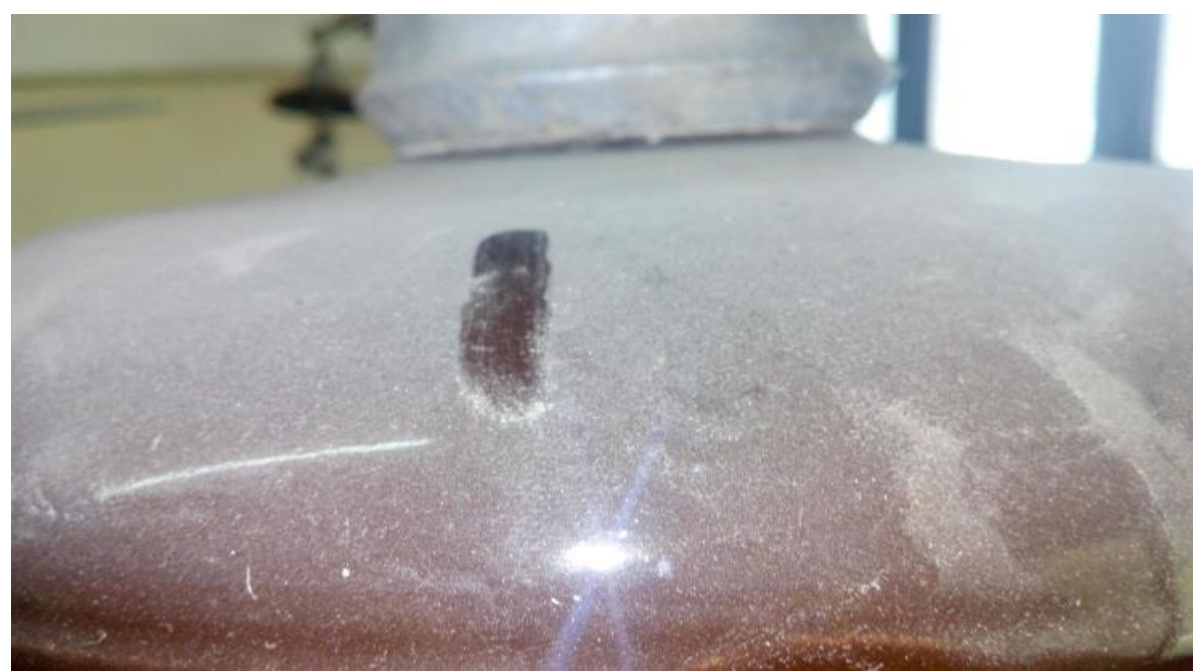

Fig. 12 (A): Uncoated Post Insulator with Formation of Dust Layer.

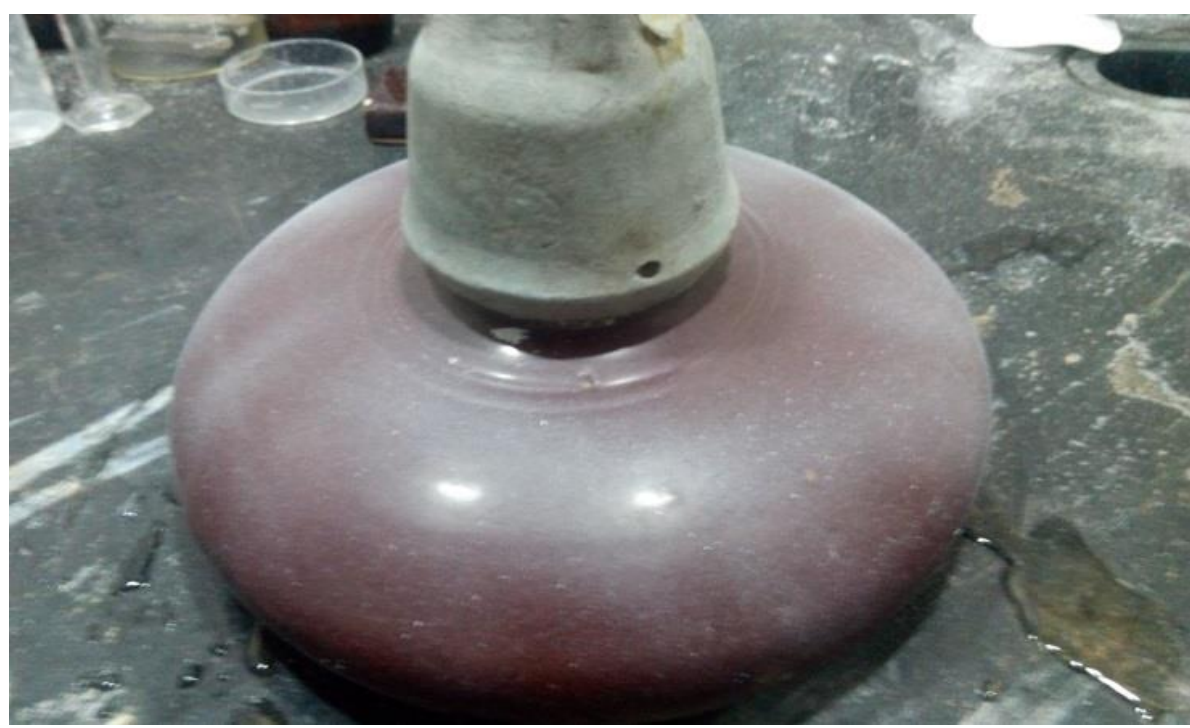

Fig. 12 (B): Coated Insulator without Any Dust Particle. 


\section{Location -2}

The insulator is found with a thick dusty layer on the uncoated insulator. The clear visual observation the coated insulator is clear from dust it could withstood the high voltage of $33000 \mathrm{~V}$ for six months, and a voltage of power frequency is applied with a gradual increase in voltage upto 33000 volts. About 15 times both the insulators are applied with an impulse voltage of 1/50 microseconds of amplitude impulse wave so that flash over may affect the insulator properties. After the tests, both the coated and uncoated insulators were observed carefully, the nano coated insulator could withstand the impulse, and uncoated insulator had a fine crack which was seen in Figure. 13 when porosity test was done on it. The insulator surface can lead to puncture of insulator and lose its insulating property in the due course of time.

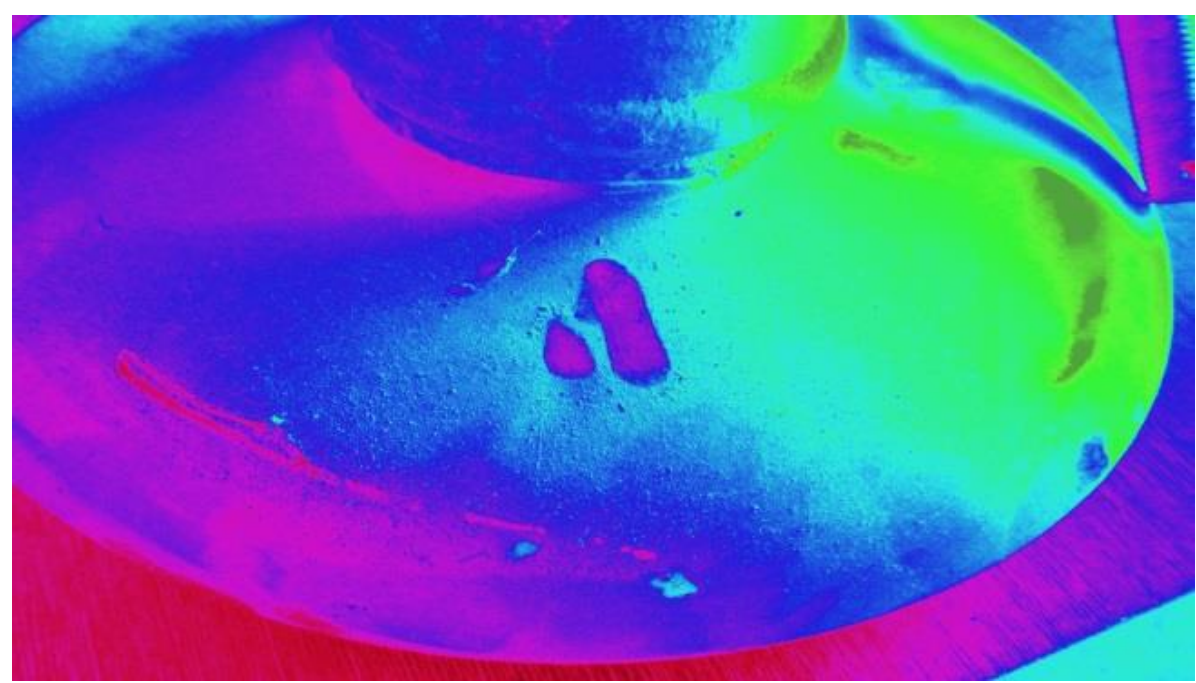

Location -3

Fig. 13: Insulator Surface Indicating a Fine Crack in Presence of Ultra Violet Light.

At this location the insulator set was covered with huge amount of dust as it was in a dusty polluted environment. The uncoated insulator at this location was covered with various amount of sand, dust pollution which got deposited on the surface of the insulator with was in ash colour as seen in the figure below, the uncoated post insulator was puncture during the rain test done in the testing laboratory, water was sprayed with a resistance of $9000 \mathrm{ohm}-\mathrm{cm}$ at an angle of 45 degrees with a volume of water precipitation of 0.12 in per minute. Under these conditions the coated insulator could withstand the rain test and no dust formation or crack was observed. The uncoated insulator was punctured in the process of testing which reveals that the insulator could not satisfy the electrical property due to heavy dust accumulation on the insulator. Figure.14 (a) and 14(b) indicates the accumulation of dust on both the insulator surface before it was taken to electrical testing laboratory.

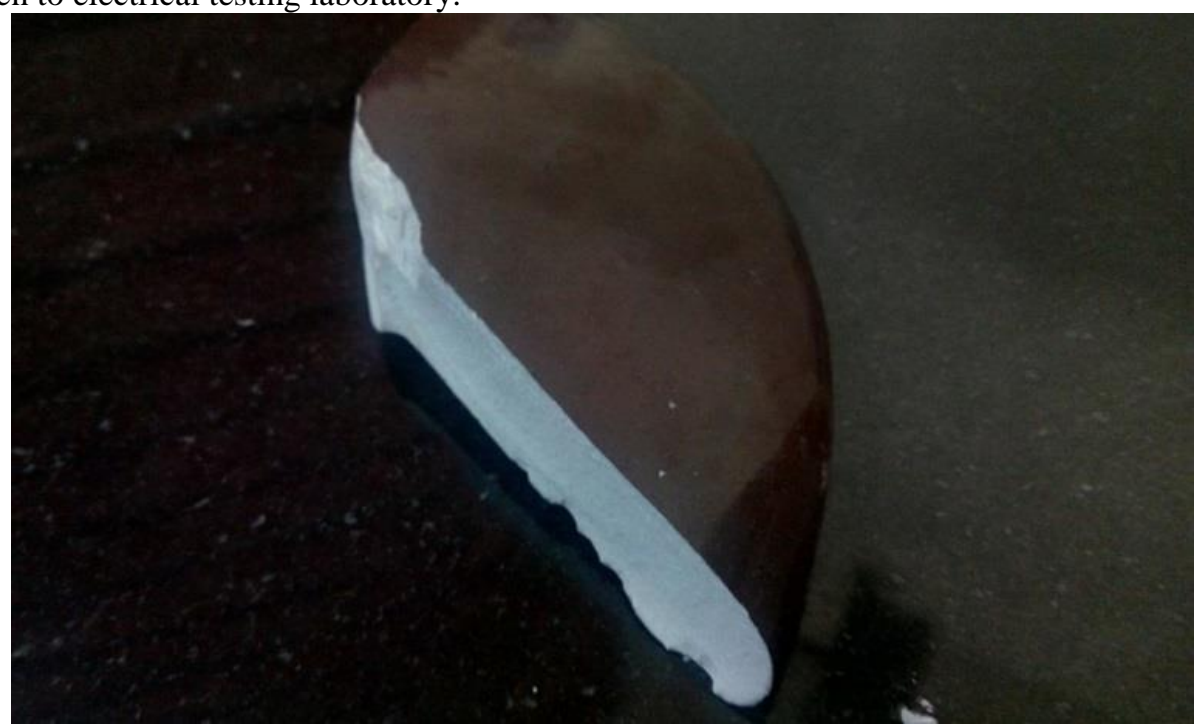

Fig. 14 (A): Broken Porcelain Insulator During Rain Test. 


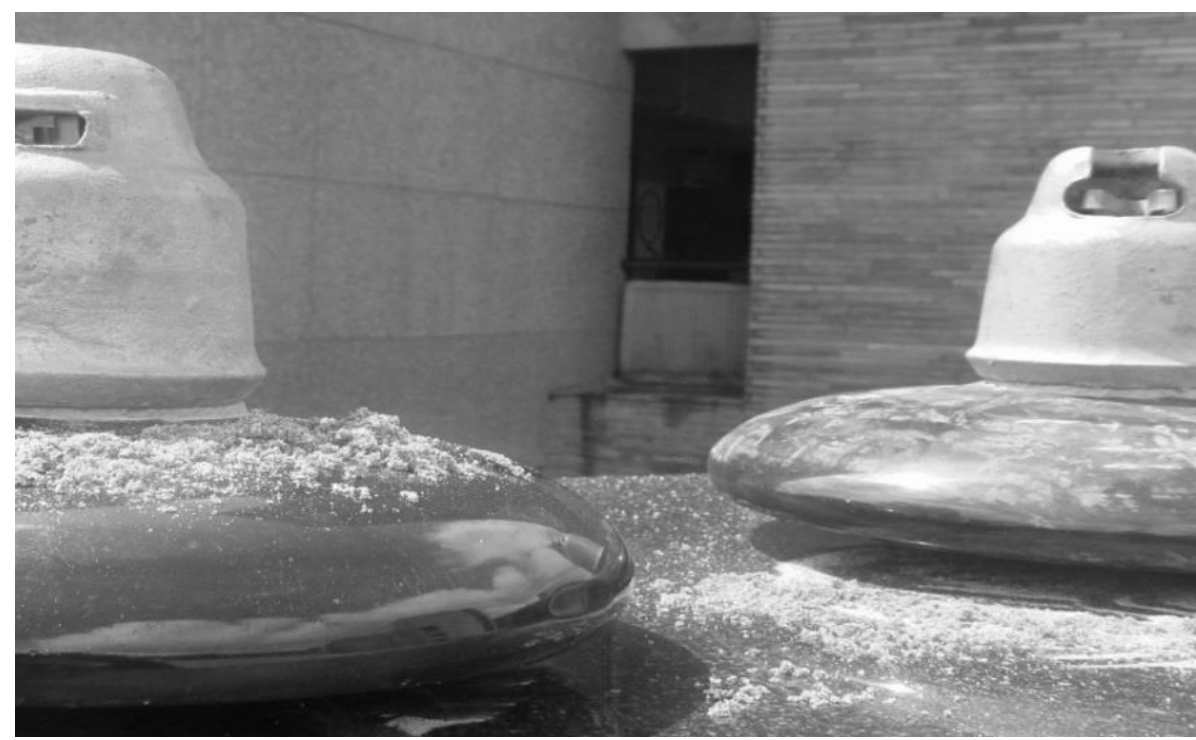

Fig. 14 (B): Left Image in the Figure: Uncoated Insulator with Deposition of Mist and Dust Still on The Surface. Right Image in the Figure: Coated Insulator with All the Deposition of Mist and Dust Roll off from the Surface of the Insulator when Both the Insulator Kept at Same Location.

\section{Conclusion}

This simple experiment on the porcelain insulators can clearly show that super hydrophobic coatings with sol-gel $\mathrm{SiO}_{2}$ silica powder above $150^{\circ}$ with good adhesion on the glass or ceramic substrates were produced by a simple single step process and economical layer sol-gel method. Nano sized, highly dispersed spherical silica particles were produced using this method. The particles were separated to various sizes by ultrasonification and used in the appropriate ratio to obtain superhydrophobicity. The insulator was kept in the different polluted industrial area where the dust formation on the insulator is negligible when compared with uncoated porcelain insulator. The dust layer formed on the insulator after a month was very less because of the super hydrophobic nature on the coated insulator. If this type of post insulators are coated with super hydrophobic powdered coating, the breakdown of power/outages due to puncture of insulators can be reduced and improve the age of the insulators on overhead lines in all conditions. During the samples are used for testing one issue was considered that the powder on the insulator surface is not so sticky and it has to be taken utmost care during handling the insulator and other glass slides. To overcome the adhesive property further research has to be made on making it more adhesive with this nano composite, and it is recommended that the insulator are to be coated on the poles with different other measures and appliances. The reagents required for these coating methods are easily available and is a simple composition and process. The cost of the coating is also a major asset for power industry. Further research and study can be done on the above two issues where the insulators puncture problems can be reduced. The economic loss due to electric insulators breakdown can be neglected.

\section{Acknowledgment}

I am sincerely grateful to Dr. Mohan Reddy for sharing his views on a number of issues related to my research work. I would like to thank Dr. Arun Kumar Chawla for providing me with the facilities required for conducting experiments in lab. It is my pleasure to thank the R \& D President Dr. Jithendra kumar Pandey from UPES and Er.PrasadKorrepati, Senior Research Scientist at M/S: OBLUM Insulators, for conducting all the electrical experiments under his supervision on the coated insulator according to the standards. It feels proud for getting the views and his guidance with Dr. Philip in Wadia Geographic Research Institute. Lastly, I am taking this opportunity to thank all the lab technicians Mr. Abhishek and Mr. Pradeep for helping me in getting the results/characterization on different instruments at University of Petroleum and Energy Studies. I thank Mr. Rajeev Divisional Engineer from tehri distribution power limited, PTCUL for sponsoring porcelain insulators and making it to be testing in live hot lines and permitting us to test the samples in high-voltage testing laboratories. Lastly, it is my pleasure to thank my research guides Dr. Rajeev Gupta and Dr. Kamal Bansal for upholding me in every situation in my research life and guiding and supporting me for successful research work in this field.

\section{References}

[1] Dussan VEB, Chow RTP (1983) J Fluid Mech 137:1-29. http://dx.doi.org/10.1017/S002211208300227X.

[2] Dussan VEB (1985) J Fluid Mech 151:1-20. http://dx.doi.org/10.1017/S0022112085000842.

[3] Dussan VEB (1987) J Fluid Mech 174:381-397. http://dx.doi.org/10.1017/S002211208700017X.

[4] Ogihara H, Xie J, Okagaki J, Saji T (2012) Langmuir28:4605-4608. 
[5] Sparks BJ, Hoff EFT, Xiong L, Goetz JT, Patton DL (2013) ACSApplied Materialinternational 5:1811-1817.

[6] Latthe SS, Imai H, Ganesan V, Venkateswara Rao A (2010)Microporous Mesoporous Material 130:115-121. http://dx.doi.org/10.1016/j.micromeso.2009.10.020.

[7] Manca M, Cannavale A, Marco LD, Arico`AS, Cingolani R, GigliG (2009) Langmuir 25:6357-6362. http://dx.doi.org/10.1021/la804166t.

[8] Peng YT, Lo KF, Juang YJ (2010) Langmuir 26:5167-5171. http://dx.doi.org/10.1021/la903646h.

[9] Lin JB, Chen HL, Fei T, Liu C, Zhang JL (2013) Applied Surface Science273:776-786. http://dx.doi.org/10.1016/j.apsusc.2013.02.134.

[10] Liu JY, Huang WQ, Xing YJ, Li R, Dai JJ (2010) J Sol-Gel Science Technology 58:18-23 http://dx.doi.org/10.1007/s10971-010-2349-8

[11] Mahadik SA, DB, Parale VG, Wagh PB, Gupta S RaoAV (2012) J Sol-Gel Science Technology 62:490-494 http://dx.doi.org/10.1007/s10971012-2753-3.

[12] Lee JP, Choi S, Park S (2011) Langmuir 27:809-814 http://dx.doi.org/10.1021/la1045354.

[13] Saleema N, Sarkar DK, Paynter RW, Chen XG (2010) Material International journal 2:2500-2502

[14] Asmatulu R, Ceylan M, Nuraje N (2011) Langmuir 27:504-507 http://dx.doi.org/10.1021/la103661c.

[15] Grignard B, Vaillant A, Coninck J, Piens M, Jonas AM,Detrembleur C, Jerome C (2011) Langmuir 27:335-342 http://dx.doi.org/10.1021/la102808w.

[16] Han D, Steckl AJ (2009) Langmuir 25:9454-9462 http://dx.doi.org/10.1021/la900660v.

[17] Islam MS, Akter N, Karim MR (2010) Colloids Surf A Physicochemical Engineering jounal Asp 362:117-120

[18] Lu XB, Zhou JH, Zhao YH, Qiu Y, Li JH (2008) Chemical Material 19:3420-3424 http://dx.doi.org/10.1021/cm800045h.

[19] Du J, O’Reilly RK (2011) ChemSoc Rev 40:2402 http://dx.doi.org/10.1039/c0cs00216j.

[20] Park BJ, Furst EM (2010) Langmuir 26:10406-10410 http://dx.doi.org/10.1021/la101030h.

[21] Wang CX, Zhang D, Xu L, Jiang YN, Dong FX, Yang B, Yu K,

[22] Lin Q (2011) AngewChem Int Ed 50:7587-7591 http://dx.doi.org/10.1002/anie.201102780.

[23] Li Y, Liu F, Sun JQ (2009) ChemCommun 19:2730-2732 http://dx.doi.org/10.1039/b900804g.

[24] Isaac et al. (2014), IOSR, pages 1-4, ISSN: $2351-615 \mathrm{X}$ 